\title{
Chapter 10 \\ Climatic, Cultural, Behavioural and Technical Influences on the Indoor Environment Quality and Their Relevance for a Regenerative Future
}

\author{
Edeltraud Haselsteiner, Marielle Ferreira Silva, and Željka Kordej-De Villa
}

\begin{abstract}
Research about indoor comfort in future years will increasingly be guided by the pressing need for decarbonizing the built environment due to climate change. Health, efficiency, and satisfaction of work and the feeling of comfort are largely determined by the interior criteria. The sustainable indoor environment is a result of complex factors: air conditioning (ventilation), indoor temperature, heating methods, lighting, and acoustic. This chapter explores and analyzes climatic, cultural, and behavioral factors that play an important role and have an influence on technology for an indoor regenerative environment. This chapter is based on an explorative literature review and reflects indoor environmental quality, users' expectations, and users' behavior from the perspective of different scientific disciplines. Current standards are based on a rational approach to thermal comfort, and indicators are determined on the measured subjects' reactions during stabilized conditions in climatic chambers. It is concluded from these results that people in different environmental conditions react similarly to everyday life. Nevertheless, survey results suggest that achieving the optimal level of the indoor environment is possible when climatic, cultural, and social context is taken into account.
\end{abstract}

Keywords Thermal comfort · Individual sensitivity and behavior · Indoor regenerative environment $\cdot$ Regenerative sustainability

\footnotetext{
E. Haselsteiner $(\bowtie)$

Urbanity - Architecture, Art, Culture and Literature, Vienna, Austria

M. Ferreira Silva

Faculty of Humanities, Education and Social Sciences, University of Luxembourg,

Esch-sur-Alzette, Luxembourg

e-mail: marielle.silva@uni.lu

Ž. Kordej-De Villa

The Institute of Economics, Zagreb, Croatia

e-mail: zkordej@eizg.hr
} 


\subsection{Introduction}

The definition of comfort and its importance is complex and will differ when regarded from various fields like social sciences, engineering, architecture, cultural anthropology, physiology, or psychology. The perception of comfort has progressed throughout history and is based on several technological, economic, social, and cultural influences. In the nineteenth century, the term was initially applied to refer to environmental comfort linked to heat, ventilation, and light (Brager \& de Dear, 2003; Rybczynski, 1986). This manner overrides the intricacy of comfort and all cultural and background factors. In reaction to conventional notions of comfort, it is proposed that it should be fluid, that is, adaptable to different possibilities, contested, and controversial, containing responses beyond energy and the environment matters (Chappells \& Shove, 2005). Nowadays, comfort is related to physical and thermal well-being and satisfaction (Brager \& de Dear, 2003; Rybczynski, 1986).

The indoor climate satisfaction and thermal comfort are the results of a balancing process between the physical environment and subjective comfort expectations. Reactions and behavior are based on experience. Thus, individual requirements and occupants' satisfaction are strongly sociocultural consignable constructs (Chappells \& Shove, 2005; Luo et al., 2016). The indoor climate is perceived individually, and the requirements are subjectively shaped. Various studies show different preferences for a comfortable indoor climate according to the origin, climate, behavioral and cultural context, and individually subjective criteria. In particular, thermal comfort depends on other parameters than physical ones. The psychological and physiological human body responds to the environment dynamically, integrating many physical phenomena as light, noise, vibration, temperature, humidity, and others (Rupp, Vásquez, \& Lamberts, 2015).

Comfort is primarily about determining ranges and their requirements, objectives, and relevances considered appropriate which are expressed in standards for particular types and uses of buildings (Cole et al., 2008). Many organizations, such as the European Committee for Standardization (CEN), the International Organization for Standardization (ISO), the American Society of Heating, Refrigeration, and Air Conditioning Engineers (ASHRAE), have each published documents setting out these guidelines in detail (Boduch \& Fincher, 2009). In addition, comfort standards will be perceived by professionals in the specific project context and the customer requirements that collectively and individually create the environment for building occupants and operators. Research studies show that psychological necessities are addressed in the planning and control strategies (Cole et al., 2008; Metz, Davidson, Bosch, Dave, \& Meyer, 2007; Owen, Frankel, \& Turner, 2007). Behavioral features of comfort are often overlooked, apart from those that fit into physiological or psychological categories (clothing, personal control, and activity level) (Cole et al., 2008).

The use of technology in construction has allowed a significant increase in comfort and the construction of energy-efficient buildings. Prior to this development of complex indoor air conditioning technologies (heating, cooling, and ventilation), it 
was essential to build buildings in close alignment with the location and the regional climate, using building materials and construction techniques available locally, and construct within the individual behavioral context of use. Today, we have increasingly moved away from this awareness, both with our knowledge and with our craft. Buildings can be constructed according to any comfort standards, without regard to external climatic conditions and regional location factors, purely through technological solutions. However, about $70 \%$ of the buildings' final energy consumption is due to lighting and air-conditioned systems. The high air conditioning energy consumption is mainly caused by invariable regulation of the inside temperature without taking the building location and outside temperatures into account (Rupp et al., 2015).

Achieving the optimal level of the indoor environment is possible when the climatic, cultural, and individual behavioral context is taken into account. This chapter explores and analyzes climatic, cultural, and behavioral factors that play an essential position and have an influence on technology for an indoor regenerative environment. Climate is a defining variable that influences culture, design of buildings, and people's behavior. These, in turn, are related to adapting or responding to the indoor climate. The chapter is based on an explorative literature review and reflects indoor environmental quality, users' expectations, and users' behavior from the perspective of different scientific disciplines. Electronic databases were used for literature research (Google Scholar and ScienceDirect). Firstly, papers were analyzed that had already carried out a comprehensive literature study on the subject (i.e., Frontczak \& Wargocki, 2011; Ortiz, Kurvers, \& Bluyssen, 2017; Rupp et al., 2015). Additionally, the method "reference by reference" was used to include the findings from further literature. As a consequence, this chapter is organized into three main sections. Section 10.2 gives an explanation and definition of restorative and regenerative sustainability and a compilation of literature that presents information about climate, cultural, and technological aspects related to human comfort. Section 10.3 discusses the documents retained from the literature search and proposes criteria for regenerative indoor environment quality. In this way, this chapter provides a new contextual insight to reconsider and rethink the aspects and criteria that influence human comfort in a wider and comprehensive perspective.

\subsection{Relationship Between Climate, Technology, and Cultural Aspects and the Comfort Criteria}

The objective of this section is to evaluate and summarize climatic, cultural, and technical factors that may indicate individual differences in the perception and evaluation of indoor environmental quality (IEQ). Based on the results, we discuss possible contributions to development toward regenerative sustainability. The following sections describe results from an exploratory literature review. In the last section, these results are discussed in terms of regenerative sustainability goals. 


\subsubsection{Comfort Criteria in the Light of Sustainability Goals}

Comfort research in the coming years will be increasingly pushed by climate change and the growing need for decarbonizing the constructed environment. The search for greater buildings' energy efficiency is driving technological development (de Dear et al., 2013). Following this trend, questions and innovations in the design of comfortable interiors are becoming progressively prominent. On the other hand, essential components on the way to solving climate change problems are urgently needed. The gap between high demands for comfort and demands for more efficient lifestyles is becoming increasingly evident.

Several definitions of sustainability are being used today, which may transmit the idea of a state in which the human beings live within the Earth's carrying capacity (Gibberd, 2003). Consequently, any debate on sustainability encompasses the continuous interaction between the human and natural processes. The conceptual base of the Millennium Ecosystem Assessment is, for instance, that humans are an inherent element of ecosystems and that a dynamic interaction between them exists, with the shifting human condition promoting, either indirectly or directly, transformations in ecosystems and thus leading to changes in human well-being (Cole, 2012).

While sustainability is defined as a strategy not to harm future generations, restorative and regenerative sustainability thinks one step more consistently toward restoring a social, ecological, and healthy balance of the environment (Brown et al., 2018). Restorative and regenerative sustainability implies considerations with the location of a building, that is, the climatic, geological, and vegetative environmental factors and also with people, their traditions, and social and cultural habits. Figure 10.1 shows the emergence of essential sustainability concepts in the direction of development toward regenerative sustainability.

Starting with the Brundtland definition of sustainability in 1987, developments followed by numerous sustainability standards (BREEAM, LEED, DGNB, WELL BUILD, RED LIST MATERIALS) and sustainability concepts (e.g., Cradle to

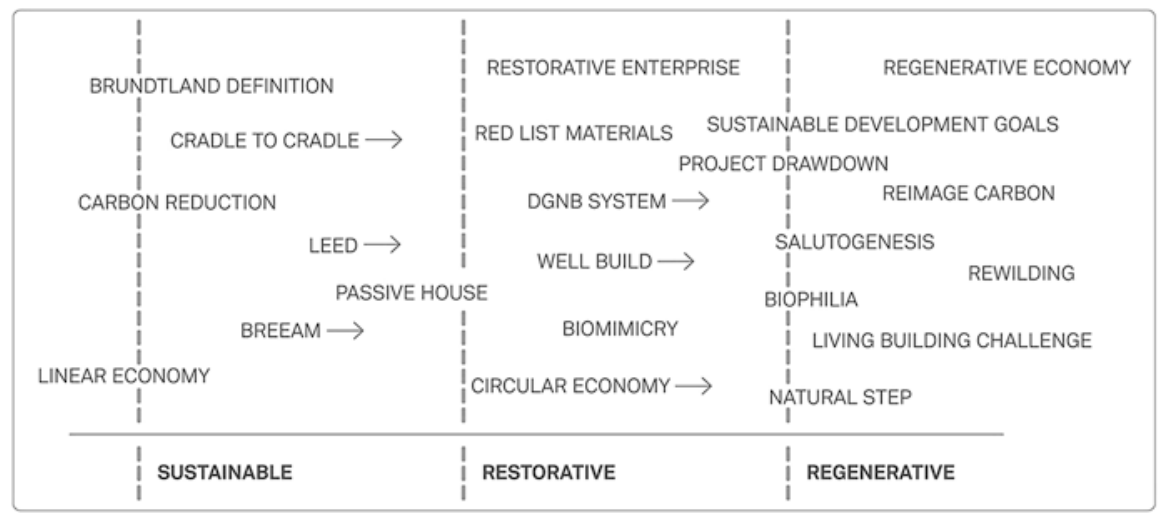

Fig. 10.1 Sustainability, restorative to regenerative (reproduced from Brown et al., 2018) 
Cradle, Passive House, Biomimicry). In order to transfer this development to regenerative sustainability in the next step, the change from a linear, growth-oriented economy to a circular economy is essential. In addition, there is a need to shift sustainability concepts from isolated orientated energy efficiency goals toward goals in harmony with nature (e.g., biophilia, salutogenesis, and rewilding). While sustainability standards for IEQ are based on a complex interplay of technical components for energy production, ventilation, heating, and cooling, regenerative sustainability relies substantially on an interplay with natural resources and people.

\subsubsection{Indoor Environmental Quality in a Climatic and Cultural Context}

Climate is a defining variable that influences culture, design of buildings, and people's behavior (Luo et al., 2016; Nicol \& Humphreys, 2002; Rupp et al., 2015; Zhang, Cao, Wang, Zhu, \& Lin, 2017). Although comfort is usually identified with thermal comfort, it also includes air quality, humidity, light, and acoustics. The interaction between thermal comfort and other indoor climate criteria, and how this affects the general satisfaction of residents, was only addressed in a few studies. The research results exhibit that thermal comfort dominates satisfaction with the indoor climate (Frontczak \& Wargocki, 2011; Rupp et al., 2015). Thermal comfort is more often rated as critical by residents than acoustic and visual comfort, and high air quality. People who are satisfied with the indoor temperature also rate other indoor qualities, such as air quality and humidity, better (Humphreys, Nicol, \& McCartney, 2002). When thermal conditions were inadequate, they diminished the comfort prospect for other indoor environmental quality (IEQ) factors. On contrary, when the thermal conditions were adequate, they raised comfort satisfaction of other IEQ features, which could lower the assessment of the actual compliance of other IEQ features retroactively (Geng, Ji, Lin, \& Zhu, 2017). Outcomes from the literature, therefore, suggest that thermal comfort should be given a particular priority over other comfort criteria.

Current standards are based on a rational approach to thermal comfort, and indicators are established regarding the reactions of determined subjects under stable conditions in climate chambers. It is concluded from these results that people in different environmental conditions react similarly to everyday life. Often, however, these values are not confirmed in field studies. Nicol and Humphreys (1973) claim that this might be the consequence of result among the respondents' well-being and their behavior adapting to the atmospheric situation where the field study was performed. Since thermal comfort is first and foremost subjectively rated and perceived, they propose an adaptive approach, largely based on field studies in naturally aerated buildings. The adaptive approach is founded on the behavior of humans to adapt to changing conditions in their environment. Thermal comfort stands in the context of three essential variables: first, the climate; second, the building with its 
services; and third, the time in which users respond to changing conditions. Indoor temperatures should be in accordance with the change in outdoor temperature. Thus, local outdoor climate should be respected (Nicol \& Humphreys, 2002). Based on Rupp et al. (2015), the adaptive model is supported by three mutually connected elements: psychological (comfort expectation related to external and internal temperature), physiological (acclimatization), and behavioral (opening windows, and the use of blinds, fans, and doors).

Acclimatization can result from personal adjustment (behavior, selection of clothes and activities, reallocation), technological modification (using shades or windows, heating or fans), cultural acclimation (implementation of daily activities, dress codes), and climate conditions (Medved, Arkar, \& Domjan, 2019). The reaction to an incentive, as well as the range of possible changes (in clothing, daily activities, etc.), will depend on social factors. Social restrictions effect is to limit number of control options available and therefore restrict the wholeness of the control gained (Nicol \& Humphreys, 1973).

Although current country-specific comparisons show that thermal expectations are converging to a winter neutral residential temperature of around $21^{\circ} \mathrm{C}$, there are still significant differences (Luo et al., 2016). Even if these countries are within the same temperature zones, studies have shown that satisfaction with thermal comfort varies significantly from country to country (Zhang et al., 2017). As an explanation for this, the technical equipment is taken into account (e.g., different heating systems), but behavioral and cultural influences are also claimed. While these differences are difficult to pinpoint based on concrete scientific results or have only been investigated in a few studies to date, there are plausible explanations for cultural and climatic adjustments. First, a behavioral adjustment, such as clothing: due to outside temperatures or cultural reasons, clothing that is better insulated against cold or heat is preferred or common. Likewise, the use of individual devices to regulate thermal comfort, for example, the use of fans in warm regions or electric blankets in cool countries. Second, long-term adaptation is inferred. On one hand, physiological differences between ethnic groups are mentioned, but also different psychological ways of thermal adaptation. For example, Zhang et al. (2017) show that the quality of insulation through clothing is considerably higher in Asia (China) compared to North America and Europe. This results in a much higher acceptance of temperatures under common comfort standards. In addition, they also provide a physiological explanation: "On the basis of heat balance, lower indoor temperature leads to more human body heat loss, which makes Chinese to wear more clothes to keep warm" (Zhang et al., 2017: 213). In addition, many research studies show that Chinese/Asians have lower basal metabolic rate than Westerns/whites (WoutersAdriaens \& Westerterp, 2008; Qi et al. 2014).

In general, people try to prevent discomfort, and therefore, they always strive (intentionally or unintentionally) to modify their current condition to more neutral or comfortable state. Consequently, many measures are aimed at health welfare (Ortiz et al., 2017). Accordingly, one should refer to well-being rather than comfort, which also includes health aspects such as stress reduction or health-promoting aspects. 


\subsubsection{Influence of Technology on Comfort Criteria and Regenerative Sustainability}

Technologies for energy conversion can affect how buildings were built to protect people from harsh environmental constraints. The internal comfort evaluation usually oriented to several physical parameters that impact how people perceive the indoor environment based on their psychological and physiological characteristics. Indoor air quality, lighting, acoustic, and thermal comfort aspects must ensure the indoor environment quality with the minimum possible energy use (Medved et al., 2019). In the context of global warming, an adequate prediction of the built environment provides occupants a comfortable thermal sensation, and further specifies the building's cooling and heating loads (Nguyen, Singh, \& Reiter, 2012).

Standards of thermal comfort are necessary to support architects and engineers in defining an internal environment in that significant percentage of the occupants of the building can experience thermal comfort. Occupants in warm climates in buildings with natural ventilation often adapt to weather variations, changing their attitude and regulating their preferences and expectations (Nguyen \& Reiter, 2014). Knowing this, the incorporation of the concept of adaptive thermal comfort into the standards makes it possible to adopt different energy efficiency approaches and respond consistently to the demands of sustainable development (Nguyen et al., 2012). In addition, the adaptive comfort approach has emerged to enlighten people's mechanisms to adapt to the immediate environment and to offer an additional methodology for assessing various thermal ambiances and situations (Nguyen \& Reiter, 2014).

Therefore, environmental adjustment using technologies is the way occupants interact with buildings, that is, switches, shutters, windows, and other controls. People who operate these mechanisms and experience temperature discomfort may affect the use of energy if systems of the building are not efficiently operated (Azizi, Wilkinson, \& Fassman, 2015). The priorities of the project are framed by the predominant model and value system of the cultural and social environment where it emerges. In the same way, the technologies implemented by society express their culture and the way they perceive and involve themselves with natural systems. The degree to which environmental concerns are accentuated in the designing of buildings is also driven by direct social issues following significant events, including uncertainty or economic instability (Cole, 2012). People are affected by climate in many ways, and these are related to adapting or responding to the indoor climate.

The complete building design process demands that the responsible team - architect, engineers (mechanical and electrical), and other developers, and the owners and residents - collaborate to define and implement energy goals (Torcellini \& Crawley, 2006). The house design allows users to control comfort in different manners: by using large open-air spaces (taking advantage of or avoid the predominant season winds), considering natural ventilation by capturing and controlling the wind through blinds (direct winds) and directional frames (crosswinds), and by night purges (windows that allow warm air without compromising safety) (Miller \& 
Buys, 2012). Heating, ventilation, and air conditioning (HVAC) system dimensioning addressing these reduced loads (Torcellini \& Crawley, 2006). The lighting is linked to the high demand for electricity, which can be reduced by intelligently adapting the lighting to daylight (Medved et al., 2019), such as daylight implementation with automated controls when available and in dim light, or even better, switching off the lights (Torcellini \& Crawley, 2006). The inclusion of a number of possibilities in the design enables higher customization to suit personalized comfort needs. This also points to the fact that "operation manuals" need to be included with homes so that residents can learn how to "run" the house to reach their designed efficiency ratings (Miller \& Buys, 2012; Torcellini \& Crawley, 2006).

Concerning the implementation of technologies and strategies, barriers for better building performances are identified. Sustainable technologies are desirable from the societal perspective because of their performance in relation to traditional solutions, although they can be unsatisfactory from the viewpoint of an individual company, which may have contradictory goals (Nelms, Alan, \& Lence, 2005). The deployment of green features for real estate proposal has to face several obstacles that conventional construction does not face, like higher design costs for green devices and energy-saving material in the design phase, long process of planning and approval of new recycled materials and green technologies, and absence of acquaintance with green technologies causing design and construction delays (Zhang, Platten, \& Shen, 2011). Furthermore, the effects of technological developments can be simultaneously challenging and complex to measure (Nelms et al., 2005). In order to comprehend and have a more amplified and real perspective of the situation, it is essential to clarify the connection among the local culture and its technology applied in a specific context to achieve human comfort.

\subsubsection{The Role of Culture and Local Context, in Understanding Technology and Comfort}

Proper technology solutions can promote a shift in building design to "more regenerative." The choice of adequate technology has to be based on assessment within the whole policy process which is affected by the local situation. The prerequisite for efficient transfer of technologies is a comprehension of a local culture. It must be recognized that the existing built environment represents an important part of local variety, values, and background. A European approach is characterized by robust public policies and state intervention in the areas of cultural heritage, built environment, and "green" topics (Kohler, 2003).

There is a prevailing consensus that the introduction of new solutions into another region with different settings is often compromised (Cole \& Lorch, 2003). In addition, solutions that are different from user expectations usually compromise the objective of creating an environmentally advanced construction. Dealing with these concerns is the real challenge for professionals who have to govern behavioral and 
cultural change to support adequate levels of comfort which also include environmental issues.

Recent research shows that one of the most important limiting factors is the inability to articulate and understand the backgrounds of local anticipations, social and cultural values, and lifestyle (Cole \& Lorch, 2003; Shields, 2003; Wu, Fan, \& Chen, 2015). The built environment can be considered as the expression of human preferences and creativity. It mirrors the expertise and priorities of its authors. According to Cole and Lorch (2003), an essential prerequisite for the development of green construction practices is the creation of competences that can modify international information to regional context. That includes cultural needs, habits, standard of living, and lifestyle, along with local weather, technologies, and materials. Therefore, ensuring the success of green buildings may require a transition time in which new training and education, together with reassessment and adaptation to changing settings, will be crucial (Cole \& Lorch, 2003: 15).

According to Leaman (2003), behaviors are culturally dependent. They reflect our attitudes to different aspects of life, but at the same time, they are also affected by regulations and different norms. Recently, building-related health standards have been changed drastically, and therefore conditions which were accepted a decade ago are now intolerable.

There are different behaviors of building users in a residential and commercial buildings. Occupants of a residential building have a higher level of influence, and they show their comfort preferences more freely. Occupants of commercial buildings rarely feel such level of control of their working environment. Besides, it is noticed that occupants of commercial buildings who experience more control can also feel a higher level of comfort. Therefore, it is widely accepted that provision and perception of comfort depend on the local context (Ackerman, 2002; Cooper, 1998; Crowley, 2001).

Today, it is essential to recognize additional features in defining the comfort. Climate change is one of them. The construction sector has been detected as a main probable actor to attenuate the climate change (Metz et al., 2007; Ürge-Vorsatz et al. 2007a, b). This will substantially influence the conventional attitudes to comfort. Depending on the approaches implemented, it offers additional incentives to reformulate and widen the range of what occupants experience as adequate indoor environments. To consider the relationships between occupants and between occupants and built environment, the whole process should be integrative, participatory, and interactive in its nature. This is contrary to the conventional approach which is predominantly linear and predictable. 


\subsection{Discussion and Conclusion: Criteria for Regenerative Indoor Environment Quality}

This chapter opens a discussion about aspects related to climatic, cultural, technology, and individual behavioral factors that can influence the indoor regenerative environment. Because of this, in order to have a more realistic development and acceptance by the occupants, the culture and local context should be taken into consideration, including social criteria implanted into the operational process.

The behavioral component of comfort considers the interactions between occupants and contains questions of the vicinity of working places and feeling of places, the position related to open and closed offices that reflect potential for isolation or contacts, sense of mutual programs, and so on. Moreover, social comfort relates to the experience of comfort mutual perceptions. This means that the full range of individual factors is taken into account.

A body of research has examined thermal comfort requirements and highlighted interlinkages with cultural and climatic conditions (i.e., Luo et al., 2016; Zhang et al., 2017). Cultural adaptation has to be taken into account, but also individual expectations and country-specific acceptance and adaptation behavior. Comparisons between different climatic zones highlight the connection between external climate and the internal environment as a significant factor (Yan and Hao 2017; Zhang et al., 2017). However, looking at IEQ from the perspective of regenerative sustainability, the required adaptation to climate, culture, and the local context is even more essential (Brown et al., 2018). Energy efficiency is still the dominant element of sustainability standards, that are partial and missing an integral scheme that takes into consideration the behavioral, cultural, and local context.

Ortiz et al. (2017) describe comfort as a response to environmental factors that is affected by cognitive and behavioral notions. We widely agree with this statement and its conclusion, but we would suggest adding the behavioral, cultural, and climatic component of comfort. In order to address the multiple facets of comfort, we must move from the conventional practice to one that aims for interactive adaptability that allows the system to address changing needs over time (Kamholz \& Storer, 2009). Furthermore, a regenerative approach asks about the relationship with nature, local resources, and the social context (Brown et al., 2018).

One path in which the construction sector is incentivizing the implementation of sustainable design concepts is the substitution of traditional technologies with those that have a smaller health, ecological, and environmental impact. Technology deployment must be founded on a comprehensive understanding and appropriate assessment of the complete scope of repercussions and project milieu associated to it, from an environmental, social, economic, and technical perspective (e.g., climatic condition, programmatic requirements, and building type). The performance of the technology in one region may differ from accomplishment in other settings (Nelms et al., 2005). In relation to technology, Labuschagne and Brent (2006) concluded that a methodology of quantitative social effect evaluation can still not be implemented for life cycle management and technology reasons. It is suggested that 
social sustainability should be embedded in the management of project and technology life cycle through the guidelines and checklists provided in Table 10.1, including also the descriptions of the standards at the respective structure levels (Labuschagne et al., 2005).

Table 10.1 Definitions of social criteria (adapted from Labuschagne, Brent, \& van Erck, 2005; Labuschagne \& Brent, 2006)

\begin{tabular}{|c|c|c|}
\hline \multirow{4}{*}{$\begin{array}{l}\text { Internal human resources } \\
\text { Social responsibility of the } \\
\text { company toward its workforce } \\
\text { including employment aspects }\end{array}$} & $\begin{array}{l}\text { Employment } \\
\text { stability }\end{array}$ & $\begin{array}{l}\text { A business initiative's impact on work } \\
\text { opportunities: the stability as well as } \\
\text { evaluating the fairness of compensation }\end{array}$ \\
\hline & $\begin{array}{l}\text { Employment } \\
\text { practices }\end{array}$ & $\begin{array}{l}\text { Evaluation of disciplinary and secrecy } \\
\text { practices, employee contracts to comply with } \\
\text { the laws of the country, human rights } \\
\text { declarations as well as fair employment } \\
\text { practice standards }\end{array}$ \\
\hline & $\begin{array}{l}\text { Health and } \\
\text { safety }\end{array}$ & $\begin{array}{l}\text { Evaluates preventive measures as well as the } \\
\text { occurrence and handling of health and/or } \\
\text { safety incidents }\end{array}$ \\
\hline & $\begin{array}{l}\text { Capacity } \\
\text { development }\end{array}$ & $\begin{array}{l}\text { Career development and higher-education } \\
\text { opportunities focus on the training of } \\
\text { employees - evaluation of the company's } \\
\text { contribution to sustainable product } \\
\text { development }\end{array}$ \\
\hline \multirow{3}{*}{$\begin{array}{l}\text { External population } \\
\text { External impacts of the } \\
\text { company on society, for } \\
\text { example, availability of } \\
\text { services, community } \\
\text { cohesion, and economic } \\
\text { welfare }\end{array}$} & Human capital & $\begin{array}{l}\text { Individual's ability to generate an income } \\
\text { and encompasses aspects such as health, } \\
\text { psychological wellbeing, education training, } \\
\text { and skills levels }\end{array}$ \\
\hline & $\begin{array}{l}\text { Productive } \\
\text { capital }\end{array}$ & $\begin{array}{l}\text { Measures and entails the resources and } \\
\text { infrastructure an individual need in order to } \\
\text { maintain a productive life }\end{array}$ \\
\hline & $\begin{array}{l}\text { Community } \\
\text { capital }\end{array}$ & $\begin{array}{l}\text { The effect of an operational initiative on the } \\
\text { social and institutional relationships and } \\
\text { networks of trust, reciprocity, and support of } \\
\text { typical characteristics of the community }\end{array}$ \\
\hline \multirow[t]{2}{*}{$\begin{array}{l}\text { Macro social performance } \\
\text { Organization contribution to } \\
\text { the environmental and } \\
\text { financial performance for } \\
\text { society }\end{array}$} & $\begin{array}{l}\text { Socio-economic } \\
\text { performance }\end{array}$ & $\begin{array}{l}\text { Addresses the external economic impact, for } \\
\text { example, economic welfare (contribution to } \\
\text { GDP, taxes, etc.) as well as trading } \\
\text { opportunities (contribution to foreign } \\
\text { currency savings, exports, etc.). }\end{array}$ \\
\hline & $\begin{array}{l}\text { Socio- } \\
\text { environmental } \\
\text { performance }\end{array}$ & $\begin{array}{l}\text { Contribution to the improvement of the } \\
\text { environment for society on a community, } \\
\text { regional, and national level. Environmental } \\
\text { monitoring abilities of society, as well as the } \\
\text { enhancement of legislation and the } \\
\text { enforcement thereof }\end{array}$ \\
\hline \multirow{2}{*}{$\begin{array}{l}\text { Stakeholder participation } \\
\text { Relationships between the } \\
\text { company and stakeholders }\end{array}$} & $\begin{array}{l}\text { Information } \\
\text { provisioning }\end{array}$ & $\begin{array}{l}\text { The quantity and quality of information } \\
\text { shared with stakeholders are measured }\end{array}$ \\
\hline & $\begin{array}{l}\text { Stakeholder } \\
\text { influence }\end{array}$ & $\begin{array}{l}\text { Evaluation of the degree of stakeholder } \\
\text { influence on the decision-making }\end{array}$ \\
\hline
\end{tabular}


Regenerative sustainability is based on the regenerative abilities of nature and humans. Bottom-up approaches that empower diverse sectors and societal interests could contribute to a broader understanding of well-being. In order to achieve goals of restorative sustainability, according to the literature reviewed in this chapter, the view of comfort must be expanded in a way to include notions of standards required for energy efficiency as well as to comprise possible interactions and differences among people. As a result, there is a potential to change the way buildings should be designed, exploring the comfort design to be friendly to the occupants, environmentally friendly, aesthetically pleasing, and economically responsible since different climatic, behavioral, and cultural aspects are taken into account beyond the IEQ references.

\section{References}

Ackerman, M. E. (2002). Cool comfort: America's romance with air conditioning. Washington, DC: Smithsonian Institution Press.

Azizi, N. S. M., Wilkinson, S., \& Fassman, E. (2015). An analysis of occupants response to thermal discomfort in green and conventional buildings in New Zealand. Energy and Buildings, 104, 191-198. https://doi.org/10.1016/j.enbuild.2015.07.012

Boduch, M., \& Fincher, W. (2009). Standards of human comfort relative and absolute. In UTSoA Seminar in Sustainable Architecture. University of Texas at Austin School of Architecture.

Brager, G. S., \& de Dear, R. J. (2003). Historical and cultural influences on comfort expectations. In R. J. Cole \& R. Lorch (Eds.), Buildings, culture and environment - Informing local and global practices (pp. 177-202). Oxford, UK: Blackwell Publishing.

Brown, M., Haselsteiner, E., Apro, D., Kopeva, D., Luca, E., Pulkkinen, K.-L., \& Rizvanolli, B. V. (2018). Sustainability, restorative to regenerative. An exploration in progressing a paradigm shift in built environment thinking, from sustainability to restorative sustainability and on to regenerative sustainability. COST Action CA16114 RESTORE.

Chappells, H., \& Shove, E. (2005). Debating the future of comfort: Environmental sustainability, energy consumption and the indoor environment. Building Research and Information, 33, 32-40. https://doi.org/10.1080/0961321042000322762

Cole, R. J. (2012). Transitioning from green to regenerative design. Building Research and Information, 40(1), 39-53. https://doi.org/10.1080/09613218.2011.610608

Cole, R. J., \& Lorch, R. (Eds.). (2003). Buildings, culture and environment - Informing local and global practices. Oxford, UK: Blackwell Publishing.

Cole, R. J., et al. (2008). Re-contextualizing the notion of comfort. Building Research and Information, 36(4), 323-336.

Cooper, G. (1998). Air conditioning America: Engineers and the controlled environment, 1900-1960. Baltimore, MD: Johns Hopkins University Press.

Crowley, J. (2001). The invention of comfort: Sensibilities and design in early modern Britain and early America. Baltimore, MD: Johns Hopkins University Press.

de Dear, R. J., Akimoto, T., Arens, E. A., Brager, G., Candido, C., Cheong, K. W. D., et al. (2013). Progress in thermal comfort research over the last twenty years. Indoor Air, 23(6), 442-461. https://doi.org/10.1111/ina.12046

Frontczak, M., \& Wargocki, P. (2011). Literature survey on how different factors influence human comfort in indoor environments. Building and Environment, 46(4), 922-937. https://doi. org/10.1016/j.buildenv.2010.10.021 
Geng, Y., Ji, W., Lin, B., \& Zhu, Y. (2017). The impact of thermal environment on occupant IEQ perception and productivity. Building and Environment, 121, 158-167. https://doi. org/10.1016/j.buildenv.2017.05.022

Gibberd, J. (2003). Building systems to support sustainable development in developing countries. CSIR Building and Construction Technology.

Humphreys, M., Nicol, J., \& McCartney, K. (2002). An analysis of some subjective assessments of indoor air-quality in five European countries. Indoor Air, 6.

Kamholz, J., \& Storer, L. (2009). Regional and historic standards of comfort. In UTSoA: Meadows Seminar Fall 2009. University of Texas at Austin School of Architecture: UTSoA.

Kohler, N. (2003). Cultural issues for a sustainable built environment. In R. J. Cole \& R. Lorch (Eds.), Buildings, culture and environment: informing local and global practices (pp. 83-109). Oxford, UK: Blackwell Publishing.

Labuschagne, C., \& Brent, A. (2006). Social indicators for sustainable project and technology life cycle management in the process industry. International Journal of Life Cycle Assessment, 11(1), 3-15. https://doi.org/10.1065/lca2006.01.233

Labuschagne, C., Brent, A. C., \& van Erck, R. P. G. (2005). Assessing the sustainability performances of industries. Journal of Cleaner Production, 13, 373-385. https://doi.org/10.1016/j. jclepro.2003.10.007

Leaman, A. (2003). User needs and expectations. In R. J. Cole \& R. Lorch (Eds.), Buildings, culture and environment: Informing local and global practices (pp. 154-177). Oxford, UK: Blackwell Publishing.

Luo, M., de Dear, R., Ji, W., Bin, C., Lin, B., Ouyang, Q., et al. (2016). The dynamics of thermal comfort expectations: The problem, challenge and implication. Building and Environment, 95, 322-329. https://doi.org/10.1016/j.buildenv.2015.07.015

Medved, S., Arkar, C., and Domjan, S. (2019). Sustainable technologies for Nearly Zero Energy Buildings: Design and evaluation methods. Springer Nature Switzerland AG.

Metz, B., Davidson, O. R., Bosch, P. R., Dave, R., \& Meyer, L. A. (Eds.). (2007). Climate change 2007: Mitigation. Contribution of working group III to the fourth assessment report of the intergovernmental panel on climate change. Cambridge, UK: Cambridge University Press.

Miller, W., \& Buys, L. (2012). Anatomy of a sub-tropical Positive Energy Home (PEH). Solar Energy, 86(1), 231-241. https://doi.org/10.1016/j.solener.2011.09.028

Nelms, C., Alan, D. R., \& Lence, B. J. (2005). Assessing the performance of sustainable technologies for building projects. Canadian Journal of Civil Engineering, 32(1), 114-128. https://doi. org/10.1139/104-102

Nguyen, A. T., \& Reiter, S. (2014). Passive designs and strategies for Low-Cost Housing using simulation-based optimization and different thermal comfort criteria. Journal of Building Performance Simulation, 7(1), 68-81. https://doi.org/10.1080/19401493.2013.770067

Nguyen, A. T., Singh, M. K., \& Reiter, S. (2012). An adaptive thermal comfort model for hot humid South-East Asia. Building and Environment, 56, 291-300.

Nicol, J. F., \& Humphreys, M. A. (1973). Thermal Comfort as part of a self-regulating system. Building Research and Practice, 1(3), 174-179. https://doi.org/10.1080/09613217308550237

Nicol, J. F., \& Humphreys, M. A. (2002). Adaptive thermal comfort and sustainable thermal standards for buildings. Energy and Buildings, Special Issue on Thermal Comfort Standards, 34, 563-572. https://doi.org/10.1016/S0378-7788(02)00006-3

Ortiz, M. A., Kurvers, S. R., \& Bluyssen, P. M. (2017). A review of comfort, health, and energy use: Understanding daily energy use and wellbeing for the development of a new approach to study comfort. Energy and Buildings, 152, 323-335. https://doi.org/10.1016/j.enbuild.2017.07.060

Owen, B., Frankel, M., \& Turner, C. (2007). The energy performance of LEED buildings. Paper presented at the Greenbuild Conference and Expo, November 2007.

Qi, M. W., Li, X. F., Weschler, L. B., \& Sundell, J. (2014). CO2 generation rate in Chinese people. Indoor Air, 24(6), 559-566. https://doi.org/10.1111/ina.12110 
Rupp, R. F., Vásquez, N. G., \& Lamberts, R. (2015). A review of human thermal comfort in the built environment. Energy and Buildings, 105, 178-205. https://doi.org/10.1016/j. enbuild.2015.07.047

Rybczynski, W. (1986). Home: A short history of an idea. New York: Viking.

Shields, R. (2003). Globalisation - Entangled places, interface buildings, generic design. In R. J. Cole \& R. Lorch (Eds.), Buildings, culture and environment: Informing local and global practices (pp. 18-36). Oxford, UK: Blackwell Publishing.

Torcellini, P. A., \& Crawley, D. B. (2006). Understanding zero-energy buildings. ASHRAE Journal, 48.

Ürge-Vorsatz, D., Harvey, L. D. D., Mirasgedis, S., \& Levine, M. D. (2007a). Mitigating $\mathrm{CO}_{2}$ emissions from energy use in the world's buildings. Building Research and Information, 35(4), 379-398.

Ürge-Vorsatz, D., Koeppel, S., \& Mirasgedis, S. (2007b). Appraisal of policy instruments for reducing buildings' $\mathrm{CO}_{2}$ emissions. Building Research and Information, 35(4), 458-477.

Wouters-Adriaens, M. P. E., \& Westerterp, K. R. (2008). Low resting energy expenditure in Asians can be attributed to body composition. Obesity, 16(10), 2212-2216. https://doi.org/10.1038/ oby. 2008.343

Wu, S., Fan, P., \& Chen, J. (2015). Incorporating culture into sustainable development: A cultural sustainability index framework for Green Buildings. Sustainable Development, 24(1), 64-76.

Yan, H., \& Hao, Z. (2017). Impacts of different climate in Northern and Southern regions on people's thermal comfort in Winter. Procedia Engineering, 205, 565-572. https://doi. org/10.1016/j.proeng.2017.10.424

Zhang, X., Platten, A., \& Shen, L. (2011). Green property development practice in China: Costs and Barriers. Building and Environment, 46(11), 2153-2160. https://doi.org/10.1016/j. buildenv.2011.04.031

Zhang, N., Cao, B., Wang, Z., Zhu, Y., \& Lin, B. (2017). A comparison of winter indoor thermal environment and thermal comfort between regions in Europe, North America, and Asia. Building and Environment, 117, 208-217. https://doi.org/10.1016/j.buildenv.2017.03.006

Open Access This chapter is licensed under the terms of the Creative Commons Attribution 4.0 International License (http://creativecommons.org/licenses/by/4.0/), which permits use, sharing, adaptation, distribution and reproduction in any medium or format, as long as you give appropriate credit to the original author(s) and the source, provide a link to the Creative Commons license and indicate if changes were made.

The images or other third party material in this chapter are included in the chapter's Creative Commons license, unless indicated otherwise in a credit line to the material. If material is not included in the chapter's Creative Commons license and your intended use is not permitted by statutory regulation or exceeds the permitted use, you will need to obtain permission directly from the copyright holder.

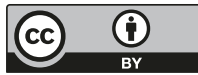

